Review Article

\title{
Dysbiosis of Oral Microflora: A Review
}

\author{
Mithra N Hegde ${ }^{1}$, Mrinalini ${ }^{2}$ \\ ${ }^{1}$ Head of the Department, ${ }^{2}$ Post Graduate Student, Department of Conservative Dentistry and Endodontics, A B Shetty \\ Memorial institute of Dental Sciences, Nitte deemed to be university, Mangaluru, Karnataka, India
}

Corresponding Author: Mithra N Hegde, Head of the Department, Department of Conservative Dentistry and Endodontics, A B Shetty Memorial institute of Dental Sciences, Nitte deemed to be university, Mangaluru, Karnataka, India.

Mobile:+919845284411E-mail:drhegdedentist@gmail.com,

$\begin{array}{ll}\text { Received } & : 15.10 .2018 \\ \text { Review Completed } & : 21.11 .2018 \\ \text { Accepted } & : 23.11 .2018\end{array}$

Keywords : Oral microbiome, dysbiosis, probiotics, maintainence of oral equilibrium

\begin{tabular}{|c|}
\hline Access this article online \\
\hline Quick Response Code \\
\hline
\end{tabular}

\begin{abstract}
:
Microorganisms being an integral part of human body colonise various sites, with oral cavity being one of the most densely populated environment. Within the oral cavity there are varying environment, properties of which determines the type of microbes colonising the site, while the metabolic activities of these microorganisms later on modifies the environmental properties. These microorganisms when in equilibrium confer health benefit however any alteration in the flora allows the pathogenic bacteria to outgrow in numbers and cause oral disease. Such alteration could be due to various factors. The present review article focuses on the various aspects of oral microbial flora, their role in the body, dysbiosis and factors influencing along with the reestablishment of normal healthy microbiome. A search was made on pubmed and scopus using keywords and 25 relevant articles published during 2000 to 2018 along with their references were included in the study.

With increasing knowledge of human microbiome, attempts are made to limit the alteration in oral ecosystem or re-establish the normal healthy flora as a part of prevention or treatment of diseases. This brings about change in approach which initially focused on elimination of microbes to maintaining their equilibrium.
\end{abstract}

\section{Introduction}

With the launchment of human microbiome project in 2007, alot of informations regarding the microbial diversity of individuals has been revealed (1). The word microbiome was coined by Joshua Lederberg to describe the ecological array of commensals, symbiotic and pathogenic microbes that inhabit our body and have been all but ignored as determinants of health and disease (2). The human microbiome comprise of 'core' microbiome and a 'variable' microbiome. Core microbiome is the one common among all individuals and mainly constitutes predominant species present in healthy conditions at varying sites of body. Variable microbiome is individual specific and is attributed to distinct lifestyle as well as phenotypic and genotypic constituents (3).

Oral cavity being an indispensable part of this microbiome is colonised by over 700 species of bacteria (4). It provides a wide variety of environmental conditions favouring growth of different microorganisms. The oral microbial profile not only varies among individuals but also within the individual, different site shows distinct microbial community (5).

The old concept of microbes being the culprit of any disease is not accepted anymore rather these oral inhabitants are said to be an important contributor for host defense and also interferes with the colonization of foreign organisms, thus benefiting the host (6). They are also related to the normal physiologic functions such as digestion, drug metabolism, synthesis of vitamins etc (7).

The microorganisms present within the biofilm forms an ecosystem, which when in equilibrium confers health benefit but in case of dysbiosis (imbalance in equilibrium) favours the growth of pathogenic bacteria ultimately resulting in oral disease. Since oral cavity is considered to be the mirror of human body so any imbalance not only affects the oral health but also systemic health. There are various influencing factors for dysbiosis, knowledge of 
which will help in prevention of the imbalance and thus, maintenance of healthy environment.

\section{Material and Methods}

A search was made on Scopus and PubMed using the keywords "human microbiome", "oral microbiome" , "dysbiosis", "oral probiotics", "oral diseases" and "role of microbes". Results were further refined based on the time duration from 2000-2018. Lastly 25 relevant articles along with their references were included in the final study.

\section{Normal Flora and Its Development}

It is almost impossible to enumerate the normal flora of oral cavity due to its diversity. Oral cavity harbours enormous number of microbes, including bacteria, fungi, viruses, etc (8). Infact, the number of microbial cells is 10 times more than that of human cells in the body (9). The human along with the inhabitant microbes form 'superorganism' (10). Usually a normal healthy flora is more diverse as phylogenetic heterogeneity is associated with greater ecosystem resilience to the changes that occur in oral environment which may be in the form of imbalance in chemicals or invasion by pathogenic microorganisms (11).

The foetus in the womb is usually sterile. The new born oral flora is generally determined by microbes present in milk, water and eventually food along with surrounding environmental conditions. The initial coloniser of oral cavity are mainly streptococci and in particular, S.salivarius, S.mitis and S.oralis $(12,13)$. These pioneer bacteria and their metabolic activity determine the successive microbiota as they change the environment creating a suitable condition for colonisation of specific microbes. Such modification could be in the form of alteration of $\mathrm{pH}$, exposing new receptors on surfaces for attachment ('cryptitopes'), or generating nutrients. Microbial succession eventually leads to a stable situation with an increased diversity (14).

\section{Role of Normal Flora}

The presence of resident micro flora is not crucial for life, but plays an important role if the host is to have a normal life(15).The perspective of seeing microorganisms has changed over a period of time. Microbial inhabitants influence the anatomy, physiology, susceptibility to pathogens, and morbidity of the host. Thus they are associated with good health and confer health benefits (16). Few of the benefits of resident flora are enlisted below:

- Role in immunity

The primary flora inhabiting soft tissue and hard tissue of oral cavity acts as a primary protective barrier preventing the colonisation of exogenous microbes (17). They compete with pathogens for habitat as well as nutrition (15). Certain microbes produce metabolites like volatile fatty acids or hydrogen peroxide or they bring about change in the local environment mainly redox potential or $\mathrm{pH}$ that suppress the growth of pathogenic bacteria. One of the commonly found bacteria, S. mutans produces mutanobactinA, which can inhibit biofilm formation by Candida albicans that is responsible for fungal infection in the oral cavity (18). Also, Streptococcus salivarius produces bacteriocin namely enocin or salivaricin which shows activity against Lancefield Group A streptococci (19, 20, 21). Bacteriocin production by these strains in the pharynx may cause reduction of pathogens as they prevent their adhesion. The production of hydrogen peroxide by members of the $S$. mitis inhibit the growth of potential periodontal pathogen like A. Actinomycetemcomitans in plaque (15)

\section{- Vitamin Synthesis}

Certain lactic acid bacteria and bifidobacterium are shown to have ability to produce vitamins (22). Few lactic acid producing bacteria are seen to be associated with production of Vitamin B12.

\section{- Normal metabolic processes:}

Microbes are seen to be associated with digestion of nutrients which are usually not digestible by human host. The microbiome contains genes that allow humans to digest certain plant polysaccharides (Rajendhran and Gunasekaran,2010) (23). Also their gene contributes to the metabolism of glycans, amino acids, xenobiotics and methanogenesis (24). Few oral commensals are said to be 
capable of gluten-degradation and thus may bring about a solution for gluten indigestion (25).

\section{Dysbiosis}

Dysbiosis or dysbacteriosis is a term which signifies microbial imbalance. In 1994, Philip D Marsh gave ecological plaque hypothesis which stated that oral disease is a result of imbalance in microflora which encourages the growth of pathogenic bacteria (26). This holds true for even two of the most common oral diseases that is dental caries and periodontal pathology (27). Even the main causative organisms of these diseases are present at healthy site but its their increasing number which allow them to manifest disease. In dental caries excess carbohydrate intake favours growth of acidogenic and aciduric bacteria which over a period of time causes demineralisation of the teeth. Whereas incase of periodontal infection mainly due to poor oral hygiene there is accumulation of plaque which later on causes deepening of pockets creating anaerobic environment thus favouring the growth of anaerobic microbes. This results in the balance tilting towards pathogenic bacteria ultimately resulting in periodontal disease. Thus, any alteration in the ecosystem affecting the flora leads to decrease in beneficial colonies and increase in pathogenicity and subsequently initiates and promotes oral diseases $(28,29)$.

\section{Factors Influencing Dysbiosis}

The oral microbial profile has changed over a period of time (16). Studies of dental calculus revealed predominance of firmicutes (highest in number), Actinobacteria, Proteobacteria, Bacteroidetes, TM7, Synergistetes, Chloroflexi, Fusobacteria, Spirochetes and Euryarchaeota in earlier times $(30,31)$. Aggregatibacter actinomycetemcomitans, Streptococcus mutans and Streptococcus mitis were also present. Certain studies revealed abundance of Tannerella forsythia, Porphyromonas gingivalis and Treponema denticola as well (31). Two additional oral taxa which were seen to be significantly higher in number in at least one ancient dental calculus sample than the Human Microbiome Project healthy cohort were Filifactor alocis and Olsenella uli.
Modern human microbiome are said to be less diverse and thus less resilient to the environmental changes (16). They are predominantly cariogenic and there is decrease in incidence of beneficial bacteria. $(31,32)$ General factors affecting the growth of oral microbe includes temperature, anaerobiosis, $\mathrm{pH}$, nutrients, host defence, host genetics and antimicrobial agents (33). However, the major shift in oral microbiome from earlier times is mainly attributed to lifestyle modification including dietary changes, injudicious use of antibiotics, increased chemical consumption (lingering pesticides), stress, newer oral hygiene practices, increase in alcohol consumption and smoking and modern technologies (32).

\section{- DIET}

Local environmental factors with diet being a predominant part influence the colonisation, growth and survival of individual microbial species. Increase in use of refined sugar over past few decades is one of the major cause for increasing incidence of cariogenic bacteria (16).

Dietary factors not only affects the microbial flora directly but also alters certain endogenous factors like salivary secretion and local resistance offered by gingival tissues to infection which in turn modulate microbial profile. Most of the oral microbes utilise carbohydrates as their energy sources. Their metabolic processes inturn affects the growth of other microbes. Sucrose metabolism by Streptococcus mutans and Streptococcus sanguis lead to acid production which influences the microbial composition (34).

\section{- STRESS}

One more attributable factor for microbial dysbiosis is psychological stress (35). In few studies role of stress hormone on periodontal pathogen has been established $(36,37)$.

It was also been noted that periodontally compromised individuals had higher concentration of cortisol (stress hormone) in the gingival crevicular fluid which is one of the factors determining the type of oral flora (38). A study conducted by Ana E. Duran-Pinedo showed increased 
activity of members belonging to fusobacterium phylum after addition of cortisol. However the exact mechanism on how stress influences oral ecology is still not deciphered (39).

\section{- ANTIBIOTICS}

Uses of antibiotics are known to alter the gut flora but oral microbiota is also affected to some extent. Even though the minor alterations are restored after a period of time but in few cases reestablishment of pre-treatment states takes upto 4 years (40). Thus, injudicious use of antibiotics not only raises the threat for development of antibiotic resistant strains but also disturbs the microbial community.

\section{- MOBILE PHONES}

Use of mobile phones has increased drastically in past few years. They are said to affect nervous system, increases cancer risk, stress and anxiety and sleep disorders (41).

Even though there are no evidences of direct effect of mobile radiations on oral flora but they are said to influence the parotid secretion which alters the salivary flow and decreases protein secretion thereby posing chances of modifying the oral flora $(42,43)$.

\section{- OTHERS}

Certain medical conditions are also seen to be associated with alteration of microflora. In a study done by T. W. MacFARLANE the change in oral microbiome in patients with Sjogrens syndrome were assessed and it showed significant increase in Candida albicans, Staphylococcus aureus, and coliform bacilli among patients (44).

Also there seem to be association of radiotherapy with dysbiosis. Such alteration in flora were said to be potent in aggravating mucositis in patients undergoing radiotherapy for nasopharyngeal carcinoma (45). Exposure to active and passive tobacco smoking and alcohol consumption had shown significant impact on the gingival and oropharyngeal flora as well. Significant increase in periodontal pathogen and respiratory pathogens were also seen. However such alteration was transient and was seen to be reversed back on cessation of smoking. The main cause of increase is pathogenic load was attributed to reduction in number of beneficial microbe allowing greater adherence of pathogens $(46,47)$.

\section{Maintenance of Equilibrium}

The methods to maintain the equilibrium of oral flora focuses on reduction of factors altering the normal flora.

Limiting the use of antibiotics, dietary modification, lifestyle modification and stress management are few such approaches (16). One more recent concept of use of probiotics and prebiotics in oral cavity has shown promising results. Probiotics are live microorganisms which when administered in adequate amounts confer a health benefit to the host. Prebiotics are compounds present in food that help the beneficial bacteria grow(48). They can be used as prevention and treatment modalities or as an adjunct to the conventional therapy (49). Till date oral probiotics has been tested for dental caries, gingivitis, periodontal pathology, peri-implant mucositis, halitosis and certain fungal infections like candidiasis. Usually normal oral flora is capable of maintaining the healthy environment but their alteration due to various factors can be re-established with the help of probiotics. However, use of probiotics in the oral cavity is still limited as the exact mechanism of action is not known and their adherence in oral cavity is still questionable (48). Antibiotics has now become an integral part of dental treatment be it endodontic therapy, periodontal treatment or surgical procedure, their use is inevitable. These antibiotics pose a threat for antibiotic resistance and also destroy the normal flora. Hence, antibiotics should be prescribed judiciously and as and when required. Limiting the use of carbohydrates and refined sugars is another way of discouraging acidogenic and aciduric bacteria. Also restriction of habits like alcohol, smoking or tobacco, maintenance of proper oral hygiene will lead to maintainence of healthy oral flora (16).

\section{Conclusion}

Recently with increasing knowledge of microbiome and its interaction with host has paved a new way we see the disease. Now, microorganisms are no more considered as the main culprit of oral diseases. It brought about shift in 
treatment approach which now focuses on maintaining the equilibrium rather elimination. However, this concept is still in its initial stage and requires further research to come

\section{References}

1. Parahitiyawa NB, et al. Exploring the oral bacterial flora: current status and future directions. Oral Diseases 2010;16:136-145.

2. The NIH Human Microbiome Project. Microbe Magazine 2009;4(9):393-393.

3. Sonnenburg J, Fischbach M. Community Health Care: Therapeutic Opportunities in the Human Microbiome. Science Translational Medicine. 2011;3(78):78ps12-78ps12.

4. Takahashi N. Microbial ecosystem in the oral cavity: Metabolic diversity in an ecological niche and its relationship with oral diseases. International Congress Series 2005;1284:103-112.

5. Aas J, Paster B, Stokes L, Olsen I, Dewhirst F. Defining the Normal Bacterial Flora of the Oral Cavity. Journal of Clinical Microbiology. 2005;43(11):5721-5732.

6. Marsh PD. Role of the oral microflora in health. Microbial Ecology in Health and Disease 2000;12:130-137.

7. Li M, Wang B, Zhang M, Rantalainen M, Wang S, Zhou H, Zhang Y, Shen J, Pang. Symbiotic gut microbes modulate human metabolic phenotypes. Proc Natl Acad Sci U S A 2008 Feb 12;105(6):2117-2122.

8. Chen T, Yu WH, Izard J, Baranova OV, Lakshmanan A, Dewhirst FE. The human oral microbiome database: a web accessible resource for investigating oral microbe taxonomic and genomic information. Database (Oxford) 2010 Jul 6;2010:baq013.

9. Ling Z, Kong J, Jia P, Wei C, Wang Y, Pan Z et al. Analysis of Oral Microbiota in Children with Dental Caries by PCR-DGGE and Barcoded Pyrosequencing. Microbial Ecology. 2010;60(3):677-690.

10. Sleator R. The human superorganism- Of microbes and men. Medical Hypotheses. 2010;74(2):214-215.

11. Adler CJ, Dobney K, Weyrich LS, Kaidonis J, Walker AW, Haak W, Bradshaw CJ, Townsend G, Soltysiak A, Alt KW, et al. Sequencing ancient calcified dental plaque shows changes in oral microbiota with dietary shifts of the Neolithic and industrial revolutions. Nat Genet 2013 Apr;45(4):450-455, 455e1.

12. Smith DJ, Anderson JM, King WF, van Houte J, Taubman MA. Ora streptococcal colonization of infants. Oral Micro-biol Immunol 1993; 8: $1-4$

13. Pearce C, Bowden GH, Evans M, Fitsimmons SP, Johnson J, Sheridan $\mathrm{MJ}$, et al. Identification of pioneer viridans streptococci in the oral cavity of human neonates. J Med Microbiol 1995; 42: 67-72

14. Marsh PD. Role of the oral microflora in health. Microbial Ecology in Health and Disease. 2000 Jan 1;12(3):130-7.

15. Batabyal B, Chakraborty S, Biswas S. Role of the oral micro flora in human population: A brief review. International Journal of Pharmacy \& Life Sciences. 2012 Dec 1;3(12)

16. Dagli N, Dagli R, Darwish S, Baroudi K. Oral microbial shift: factors affecting the microbiome and prevention of oral disease. J Contemp Dent Pract. 2016 Jan 1;17(1):90-6.

17. Marsh PD. Contemporary perspective on plaque control. $\mathrm{Br}$ Dent J 2012 Jun 22;212(12):601-606

18. Marsh PD, Head DA, Devine DA. Ecological approaches to oral biofilms: control without killing. Caries Res 2015;49 (Suppl 1):46-54.

19. Chaudhary $M$ and Payasi A. Battling the Methicillin-Resistant Staphylococcus aureus Biofilm Challenge with Vancoplus. J Microbial Biochem Technol. 2014;S10-001.

20. Bueno J. Anti-Biofilm Drug Susceptibility Testing Methods: Looking for New Strategies against Resistance Mechanism. J Microbial Biochem Technol. 2014;S3-004

21. Baier RE, et al. Suppressing Biodiversity in the World's Waterbodies: Ballast Biofilms are the Dental Plaque of the Oceans. J Biodivers Biopros Dev. 2014;1:109.

22. Rajendhran J, Gunasekaran P. Human microbiomics. Indian Journal of up with options which mainly emphasise on preventing dysbiosis and re-establishing the normal flora.

Microbiology. 2010;50(1):109-112.

23. Rajendhran J, Gunasekaran P (2010). Human microbiomics. Indian J Microbiol 50: 109-112.

24. Gill SR, Pop M, Deboy RT, Eckburg PB, Turnbaugh PJ, Samuel BS, Gordon JI, Relman DA, Fraser-Liggett CM, Nelson KE. Metagenomic analysis of the human distal gut microbiome. Science 2006 Jun 2;312(5778) 1355-1359.

25. Helmerhorst EJ, Zamakhchari M, Schuppan D, Oppenheim FG. Discovery of a novel and rich source of gluten-degrading microbial enzymes in the oral cavity. PLoS One 2010 Oct 11;5(10):e13264.

26. Rosier BT, De Jager M, Zaura E, Krom BP. Historical and contemporary hypotheses on the development of oral diseases: are we there yet? Frontiers in cellular and infection microbiology. 2014 Jul16;4:92.

27. Patil S, Rao RS, Sanketh DS, Amrutha N. Microbialflora in oral diseases. The journal of contemporary dental practice. 2013 Nov 1;14(6):1202.

28. Takahashi N. Microbial ecosystem in the oral cavity: Metabolic diversity in an ecological niche and its relationship with oral diseases. International Congress Series 2005;1284:103-112.

29. Marsh PD. Dental plaque as a biofilm and a microbial communityimplications for health and disease. BMC Oral Health 2006;6(14):1-7.

30. Henry AG, Brooks AS, Piperno DR. Microfossils in calculus demonstrate consumption of plants and cooked foods in Neanderthal diets (Shanidar III, Iraq; Spy I and II, Belgium). Proc Natl Acad Sci U S A 2011 Jan 11;108(2):486-491.

31. Warinner C, Rodrigues JF, Vyas R, Trachsel C, Shved N, Grossmann J, Radini A, Hancock Y, Tito RY, Fiddyments S, et al. Pathogens and host immunity in the ancient human oral cavity. Nat Genet 2014 Apr;46(4):336-344

32. Adler CJ, Dobney K, Weyrich LS, Kaidonis J, Walker AW, Haak W, Bradshaw CJ, Townsend G, Soltysiak A, Alt KW, et al. Sequencing ancient calcified dental plaque shows changes in oral microbiota with dietary shifts of the Neolithicand industrial revolutions. Nat Genet 2013 Apr;45(4):450-455,455e1.

33. Ali SM, Tanwir F. Oral microbial habitat a dynamic entity. Journal of oral biology and craniofacial research. 2012 Sep 1;2(3):181-7

34. Morhart RE, Fitzgerald RJ. Nutritional determinants of the ecology of the oral flora. Dental Clinics of North America. $1976 \mathrm{Jul} ; 20(3): 473-89$.

35. Gur T, Worly B, Bailey M. Stress and the Commensal Microbiota: Importance in Parturition and Infant Neurodevelopment. Frontiers in Psychiatry. 2015;6.

36. Jentsch H, März D, Krüger M. The effects of stress hormones on growth of selected periodontitis related bacteria. Anaerobe. 2013;24:49-54

37. Roberts A, Matthews J, Socransky S, Freestone P, Williams P, Chapple I. Stress and the periodontal diseases: effects of catecholamines on the growth of periodontal bacteria in vitro. Oral Microbiology and Immunology. 2002;17(5):296-303.

38. Rai B, Kaur J, Anand S, Jacobs R. Salivary Stress Markers, Stress, and Periodontitis: A Pilot Study. Journal of Periodontology. 2011;82(2):287-292.

39. Duran-Pinedo AE, Solbiati J, Frias-Lopez J. The effect of the stress hormone cortisol on the metatranscriptome of the oral microbiome. npj Biofilms and Microbiomes. 2018 Oct 18;4(1):25.

40. Jakobsson HE, Jernberg C, Andersson AF, Sjölund-Karlsson M, Jansson JK, Engstrand L. Short-term antibiotic treatment has differing longterm impacts on the human throat and gut microbiome. PLoS One 2010 Mar 24;5(3):e9836.

41. Naeem Z. Health risks associated with mobile phones use International journal of health sciences. 2014 Oct;8(4).

42. Goldwein O, Aframian DJ. The influence of handheld mobile phones on 
human parotid gland secretion. Oral Dis 2010 Mar;16(2):146-150.

43. Hamzany Y, Feinmesser R, Shpitzer T, Mizrachi A, Hilly O, Hod R, Bahar G, Otradnov I, Gavish M, Nagler RM. Is human saliva an indicator of the adverse health effects of using mobile phones? Antioxid Redox Signal 2013 Feb 20;18(6):622-627.

44. MacFarlane TW, Mason DK. Changes in the oral flora in Sjögren's syndrome. Journal of clinical pathology. 1974 May 1;27(5):416-9.

45. Hou J, Zheng H, Li P, Liu H, Zhou H, Yang X. Distinct shifts in the oral microbiota are associated with the progression and aggravation of mucositis during radiotherapy. Radiotherapy and Oncology. 2018 May 4.
46. Brook I. The impact of smoking on oral and nasopharyngeal bacterial flora. Journal of dental research. 2011 Jun;90(6):704-10.

47. Thomas AM, Gleber-Netto FO, Fernandes GR, Amorim M, Barbosa LF, Francisco AL, de Andrade AG, Setubal JC, Kowalski LP, Nunes DN, DiasNeto $E$. Alcohol and tobacco consumption affects bacterial richness in oral cavity mucosa biofilms. BMC microbiology. 2014 Dec;14(1):250.

48. Pandya D. Benefits of Probiotics in Oral cavity- Detailed Review. Ann Int Med dent Res. 2016;2(5):10-7.

49. Bowen DM. Probiotics and oral health. American Dental Hygienists Association. 2013 Feb 1;87(1):5-9 